\title{
Abusive supervision and moral courage: does moral efficacy matter?
}

\author{
Ahmed Mohammed Sayed Mostafa \\ Faculty of Commerce, Assiut University, Assiut, Egypt
}

\begin{abstract}
Purpose - The purpose of this paper is to examine the role of both supervisory abuse and moral efficacy in the weakening or strengthening of moral courage. The study also tests how the interaction between both could influence moral courage.
\end{abstract}

Design/methodology/approach - Cross-sectional data were collected from a sample of public hospital nurses in Egypt and structural equation modeling was used to analyse the data.

Findings - The study findings revealed that abusive supervision is negatively related to moral courage whereas moral efficacy is positively related to courage. Furthermore, moral efficacy moderates the abusive supervision-moral courage relationship in such a way that the negative association between abusive supervision and moral courage is reduced when moral efficacy is high.

Research limitations/implications - Because of the cross-sectional design of the study, inferences regarding causality cannot be made. Furthermore, more research is needed to identify whether the results of this study apply in other contexts.

Practical implications - Organizations should identify abusive supervisors and offer them abuseprevention training to circumvent their hostile behaviour. Organizations should also try to consider follower moral efficacy when matching supervisors with followers.

Originality/value - The study addresses calls for research on the personal factors that could mitigate the undesirable effects of abusive supervision.

Keywords Egypt, Abusive supervision, Moral courage, Moral efficacy

Paper type Research paper

\section{Introduction}

Moral courage is the fortitude to translate moral or ethical intentions into actions in spite of pressures to not to do so (May et al., 2003). It is a "critical factor" in identifying whether individuals will step up and act in accordance with their values and beliefs (Hannah et al., 2011a, 2011b, p. 556). In spite of being viewed as essential to ethical conduct at work, empirical research on moral courage and its antecedents in organizations is rare (Hannah and Avolio, 2010; Hannah et al., 2011a, 2011b; May et al., 2014). Because of this, there is a very limited understanding of the factors that could bolster or undermine moral courage (Hannah et al., 2011a, 2011b). This study seeks to address this issue by examining the role of supervisory abuse, a contextual factor, and moral efficacy, a mental process, in the

(C) Ahmed Mohammed Sayed Mostafa. Published in PSU Research Review. Published by Emerald Publishing Limited. This article is published under the Creative Commons Attribution (CC BY 4.0) licence. Anyone may reproduce, distribute, translate and create derivative works of this article (for both commercial and non-commercial purposes), subject to full attribution to the original publication and authors. The full terms of this licence may be seen at http://creativecommons.org/licences/by/4.0/legalcode

\section{Abusive supervision and moral \\ courage}

Received 13 August 2018 Revised 12 February 2019 27 May 2019 Accepted 8 July 2019

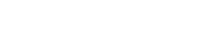


PRR

3,2

weakening or strengthening of morally courageous responses. The study also tests how the interaction between both could influence moral courage.

Abusive supervision simply refers to a "prolonged emotional or psychological mistreatment of subordinates” (Harvey et al., 2007, p. 265). Moral efficacy, on the other hand, could be defined as individuals' beliefs that they can handle effectively what is required to achieve moral performance (Hannah and Avolio, 2010). Drawing on behavioural plasticity theory, this study proposes that the negative association between abusive supervision and moral courage will be reduced when moral efficacy is high. Behavioural plasticity theory posits that individuals with high efficacy are less likely to be influenced by external cues (Eden and Aviram, 1993). This means that employees high in moral efficacy are less likely to be negatively affected by their abusive supervisors. Therefore, moral efficacy could act as a buffer to ease the negative consequences of abusive supervision on employees' moral courage.

The study makes a number of contributions to the literature. First, most of the previous research on the relationship between leadership and ethical outcomes in organizations has mainly focused on positive forms of leadership such as ethical leadership. However, less is known about the role of undesirable leadership behaviours on ethical outcomes (Hannah et al., 2011a, 2011b, 2013). This study seeks to address this issue by examining the relationship between abusive supervision and subordinates moral courage. Second, although moral efficacy is believed to be an "important contributor" to the desire and decision to engage in morally courageous acts (Sekerka and Bagozzi, 2007, p. 137), very little is known empirically about whether individual differences in efficacy beliefs could "contribute to the understanding of moral courage" (Baumert et al., 2013, p. 1055). This study seeks to address this limitation by examining the relationship between moral efficacy and moral courage. Finally, even though prior research has shown the negative consequences of supervisor abuse, not much is known about the personal factors or potential moderators that could mitigate the undesirable effects of this type of supervision (Harvey et al., 2007; Tepper et al., 2017). Identifying such factors or moderators is essential because personal differences may allow some employees to cope with this type of abuse more effectively than others (Tepper, 2000). This study, therefore, seeks to contribute to the literature by testing how moral efficacy interacts with abusive supervision to influence moral courage. As mentioned before, the study proposes that the negative relationship between abusive supervision and moral courage is reduced when employees are high, rather than low, on moral efficacy.

The rest of this paper is structured as follows. First, the direct link between abusive supervision and moral courage is discussed. This is followed by an overview of how moral efficacy could moderate the relationship between both variables. Following the description of the methodology, the results of testing the proposed hypotheses are presented. The final section of the paper discusses the implications of the findings for research and practice.

\section{Abusive supervision and moral courage}

Abusive supervision has received considerable attention from scholars in the past decade or so (Priesemuth, 2013). It is defined as an employee's subjective assessment of the degree to which his or her supervisor engages in the sustained or enduring display of hostile nonverbal and verbal behaviours, apart from physical contact (Tepper, 2000). Abusive supervision includes actions such as rudeness, coercion, public criticism and loud tantrums. Thus, it constitutes "counternormative behaviour" that employees view as inimical, degrading and offensive (Zhang et al., 2014, p. 1157). 
Abusive supervision is subjective because the same employee could perceive a supervisor's behaviour as abusive in one context and nonabusive in another, and because different employees could differ in their assessment of the same supervisor's behaviour. It is also sustained because the abuse is likely to continue until its target terminates the relationship, or the abuser terminates the relationship, or modifies his or her behaviour. Moreover, abusive supervision is wilful because supervisors engage in abusive behaviour for a reason such as causing harm or hurting others feelings or even eliciting high task performance (Tepper, 2000, 2007).

Research indicates that abusive supervisors' behaviour usually leads to employee frustration, alienation and feelings of helplessness (Ashforth, 1994). Abusive supervision has also been found to be associated with adverse work attitudes and behaviours, as well as reduced levels of wellbeing (Tepper, 2000; Harvey et al., 2007; Tepper, 2007; Sulea et al., 2013). This study proposes that abusive supervision is more likely to be negatively related to moral courage.

Moral courage is generally viewed as a "critical factor" in promoting ethical behaviour in organizations (Hannah et al., 2011a, 2011b, p. 676). It has been defined as "a prosocial behaviour with high social costs and no (or rare) direct rewards for the actor" (Osswald et al., 2009, p. 150). Moral courage usually involves behaving bravely with the intention of enforcing ethical and societal norms without taking into account an individual's own social costs (Greitemeyer et al., 2006).

Contrary to other types of courage (e.g. physical courage) which are usually motivated by a desire to save face or gain esteem, moral courage is usually motivated by a moral cause and includes elements such as moral principles, goals and intentions (Hannah and Avolio, 2010; Olsthoorn, 2013). Also, in contrast to other prosocial behaviours (e.g. helping) which are usually associated with positive social consequences such as admiration or praise, moral courage is usually associated with negative social consequences such as being attacked, excluded or insulted (Greitemeyer et al., 2006; Osswald et al., 2009).

Moral courage is believed to be "malleable" and likely to be influenced by contextual factors in the organization such as leadership (Hannah et al., 2013, p. 581). When employees encounter abusive supervision, they usually find it difficult to behave ethically and in a morally courageous way because it would be risky for them to do so. Prior research suggests that individuals fear to confront abusive supervisors because of the asymmetry in power (Tepper et al., 2007; Tepper et al., 2009; Hannah et al., 2013). Subordinates could hardly rise to the ethical or moral challenge made by abusive supervisors because the power gap or difference usually discourages subordinates from directly challenging or opposing such supervisors (Hannah et al., 2013).

An abusive supervisor may demean his subordinates and increase their fear of punishment if they act morally or speak up in favour of their ethical principles (Hannah et al., 2013). Employees, therefore, may withhold morally courageous acts so as to avoid relational deterioration or decay and alleviate their supervisors' hostile behaviour (Tepper et al., 2007; Tepper et al., 2009). In fact, prior research has shown that employees are more likely to respond to abusive supervisors by engaging in avoidance behaviours so as to reduce the discomfort associated with their hostility (Aquino et al., 2006; Tepper et al., 2007). This is in line with power-dependence theory (Emerson, 1972) which postulates that, in relationships in which there is an imbalance of power, those with less power are constrained in terms of their ability to behave in ways that satisfy their desires, beliefs and self-interests (Tepper et al., 2009).

Furthermore, as suggested by social exchange theory (Cropanzano and Mitchell, 2005), hostile treatment form supervisors is usually associated with unfavourable responses from 
PRR

3,2

subordinates because of the negative reciprocity norm. However, because of the power differential between supervisors and subordinates, subordinates will seek to restore the balance of the exchange relationship while also ensuring that their supervisors will not retaliate (Rafferty and Restubog, 2011). This will more likely be through withholding prosocial behaviours that enforce ethical norms. Thus, applying both power-dependence theory and social exchange theory, one of the ways in which an individual is likely to reciprocate negative treatment from supervisors and at the same time minimize negative consequences is to hold back or minimize morally courageous acts (Rafferty and Restubog, 2011; Wang and Jiang, 2015). Accordingly, and in line with prior research findings on the association between supervisory abuse and prosocial behaviours in organizations (Rafferty and Restubog, 2011; Hannah et al., 2013; Wang and Jiang, 2015), this study proposes that abusive supervision undermines subordinates moral courage:

H1. Abusive supervision will be negatively related to employees' moral courage.

\section{Abusive supervision and moral courage: moral efficacy as a moderator}

Moral efficacy refers to people's beliefs in their abilities to positively deal with ethical issues at work and handle hurdles to developing and applying ethical solutions to ethical problems (May et al., 2014). More simply, it is the "belief that one is capable of acting effectively as a moral agent" (Schaubroeck et al., 2012, p. 1062). Moral efficacy is a key psychological determinant of the levels of moral motivation and action (Hannah et al., 2011a, 2011b).

Osswald et al. (2009) argue that before individuals could act with moral courage, they need to feel competent to act. Moral efficacy is believed to be "one likely foundation for moral courage" as it usually takes great confidence in a person's own abilities to defend and explain courageous moral actions and deal with any resistance to them (May et al., 2014, p. 71).

Moral efficacy could enhance an individual's level of perseverance in face of ethical challenges and difficulties, which would be useful in stimulating a desire to act in a morally courageous way (Sekerka and Bagozzi, 2007). Moral efficacy also provides individuals with a sense of perceived control over their actions and their power or ability to perform. This sense of control helps explain the connection between intentions and behaviours (Hannah and Avolio, 2010). Accordingly, increased levels of moral efficacy usually increase the likelihood of individuals converting moral intentions into actions (Schaubroeck et al., 2012). All this suggests that moral efficacy helps increase moral courage. In support of these arguments, Lee et al. (2017) found that moral efficacy is positively related to the act of speaking boldly against unethical issues in organizations. Hence, the following hypothesis is proposed:

H2. Moral efficacy will be positively related to employees' moral courage.

Moral efficacy could be viewed as a resource that helps employees effectively cope with abusive supervision (Zhang et al., 2014). Individuals with high moral efficacy usually view themselves positively and strongly believe in their ability to handle work practices and issues that are against established moral standards (Lee et al., 2017). Such employees have a high degree of self-confidence and are effective in dealing with unfavourable situations and hardships (Saks and Ashforth, 2000). For these employees, being abused is incompatible with their capability and competence. Because of their lack of dependence on external cues, such employees are less likely to take this incompatibility personally and are more likely to focus on the favourable aspects of their jobs (Zhang et al., 2014). As a result of this, 
employees with high moral efficacy are more likely to maintain their commitment to moral and developmental goals, and behave courageously to enforce ethical norms even when abused by their supervisors. This is in line with behavioural plasticity theory, which postulates that individuals with low efficacy are more vulnerable to external factors or forces than high efficacy individuals (Eden and Aviram, 1993). More specifically, in organizational settings, high efficacy individuals are more likely to be "behaviourally plastic" and are less likely to be influenced by their work environment conditions and organizational characteristics (Saks and Ashforth, 2000, p. 46). Therefore, the negative influence of abusive supervision on moral courage is more likely to be reduced when employees are high, rather than low, on moral efficacy:

H3. Moral efficacy will moderate the relationship between abusive supervision and moral courage such that the negative relationship between abusive supervision and moral courage will be weakened when followers are high on moral efficacy.

Figure 1 outlines the conceptual model of this study.

\section{Sample and procedure}

The study data were collected from a sample of nurses in a large public hospital in Egypt using a paper and pen questionnaire. To minimize the risk of social desirability bias, the nurses were contacted directly and the questionnaires were given to them at work on a faceto-face basis. They were also promised anonymity and confidentiality (Bottomley et al., 2016).

Out of 350 distributed questionnaires, 204 were given back, producing a response rate of 58.3 per cent. Most of the nurses in the sample were female (93 per cent). More than half of them (55.4 per cent) were between 20 and 30 in age, 27 per cent were aged between 31 and 40, and the remainder were above 40 . As for length of service, 39 per cent had worked in the hospital for more than 15 years, 19 per cent had worked for between 10 and 15 years, and the rest had been working in the hospital for below 10 years.

\section{Measures}

The questionnaire was translated from English into Arabic using Brislin's (1970) backtranslation method and was then pre-tested by three nurses from the participating hospital. Responses to all questionnaire items were on a seven-point response scale where $1=$ strongly disagree and $7=$ strongly agree.

Abusive supervision. Eight items developed by Tepper (2000) were used to measure supervisor abuse. A sample item is "My supervisor puts me down in front of others". Cronbach's alpha for this scale was 0.894 .

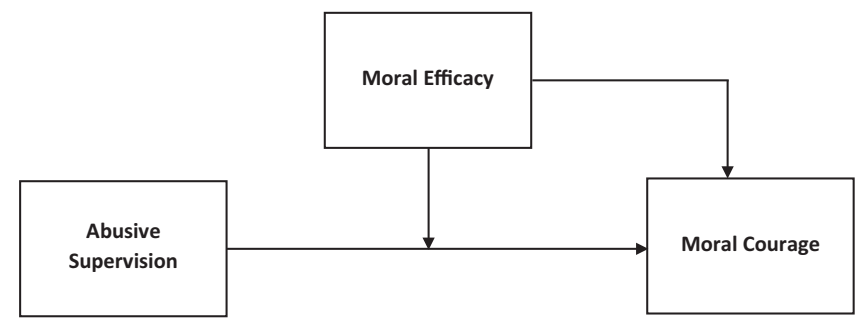

Figure 1. Conceptual model 
PRR

3,2

Moral courage. A four item scale developed by May et al. (2014) was used to measure moral courage. An item from this scale is "I would prefer to remain in the background even if a friend is being taunted or talked about unfairly" (reverse coded). Cronbach's alpha for the moral courage scale was 0.777 .

Moral efficacy. Four items from the scale developed by May et al. (2014) were used to assess moral efficacy. An example of an item from this scale is "I am confident in my ability to present information about ethical issues to my colleagues". Cronbach's alpha for the moral efficacy measure was 0.720 .

\section{Analysis}

Structural equation modeling (SEM) with AMOS 24 was used to analyse the data and test the proposed model. The measurement model was first validated and then the structural model was estimated (Anderson and Gerbing, 1988).

\section{Measurement model}

Confirmatory factor analysis (CFA) was conducted to assess the reliability and validity of the study variables. The fit of the overall measurement model was good $\left(\chi^{2}(\mathrm{df}=17)=\right.$ 38.076, $p<0.01$; CFI $=0.977$, RMSEA $=0.078$ and TLI $=0.962$ ). The three variables (i.e. abusive supervision, moral courage and moral efficacy) had high internal consistency where the composite reliability scores for all were greater than 0.80 and the average variance extracted (AVE) scores were more than 0.50 (Fornell and Larcker, 1981). Discriminant validity was also achieved where, as shown in Table I, the square root of the AVE of each variable was greater than the interconstruct correlations (Fornell and Larcker, 1981).

\section{Common method bias}

As the data were collected from the same respondents and at the same time, the potential influence of common method bias was also examined. The common method factor approach was used (Chang et al., 2010). This approach involves estimating a measurement model in which indicators are allowed to load on their theoretical construct and a common factor. The fit of this model was very good $\left(\chi^{2}(\mathrm{df}=9)=9.557, p>0.05\right.$; $\mathrm{CFI}=0.999$, RMSEA $=0.017$ and TLI $=0.998$ ). However, more importantly, the variance extracted by the common factor was 0.324 , which is lower than the 0.50 criterion suggested by Fornell and Larcker (1981) as indicative of the presence of a substantive construct. Thus, common method bias did not seem to be an issue in this study.

Table I.

Descriptive statistics, intercorrelations and reliability estimates

\begin{tabular}{lclc}
\hline Construct & \multicolumn{1}{c}{1} & \multicolumn{1}{c}{3} \\
\hline 1. Abusive supervision & $0.869,(0.925)$ & & \\
2. Moral courage & $-0.239^{* *}$ & $0.852,(0.841)$ & \\
3. Moral efficacy & $-0.242^{*}$ & $0.247^{*}$ & $0.851,(0.825)$ \\
Mean & 2.550 & 6.038 & 5.340 \\
SD & 1.360 & 0.913 & 1.130
\end{tabular}

Notes: Sub-diagonal entries are the latent construct inter-correlations. The first entry on the diagonal is the AVE square root, whereas the second entry (in brackets) is the composite reliability; $p<0.05 ; \stackrel{* * *}{p} p<0.01$ 


\section{Structural model and hypotheses}

Little et al.'s (2006) residual centring approach was used to test the moderating role of moral efficacy on the relationship between abusive supervision and moral courage because it has more power in detecting interactions than standard multiple regression. The approach involves multiplying together one indicator from each construct (i.e. abusive supervision and moral efficacy) and then regressing the cross-product on all indicators of both constructs and saving the residuals. The procedure is repeated for each cross-product and the residuals are then treated as indicators of the latent interaction term in the structural model. Correlated covariances are estimated between the indicators if the actual crossproduct included the same first-order indicator (Little et al., 2006).

Sociodemographic variables such as gender, age and tenure are generally viewed as "important control variables in ethics research" (Zhu et al., 2011, p. 155). Therefore, these variables were used as controls in the structural model. The fit of the structural model was $\operatorname{good}\left(\chi^{2}(\mathrm{df}=132)=263.783, p<0.01 ; \mathrm{CFI}=0.957, \mathrm{RMSEA}=0.070\right.$ and TLI $\left.=0.944\right)$. In this model, the predictor variables explained 24.5 per cent of the variance in moral courage $\left(R^{2}=0.245\right)$.

As predicted in $H 1$, abusive supervision was negatively related with moral courage ( $\beta=$ $-0.136, p<0.01)$. Also, consistent with $H 2$, moral efficacy was positively related with moral courage ( $\beta=0.232, p<0.01$ ). Finally, the interaction term of abusive supervision and moral efficacy was significant and positive $(\beta=0.150, p<0.01)$. This indicates that, as employees moral efficacy increased, the negative relationship between abusive supervision and moral courage decreased. Therefore, $H 3$ was also supported. Figure 2 shows the moderating role of moral efficacy on the relationship between abusive supervision and moral courage.

\section{Discussion}

There is a very limited understanding of the factors that could bolster or undermine moral courage in organizations. This study sought to address this issue by examining the role of both supervisory abuse and moral efficacy in the weakening or strengthening of moral courage. In line with the proposed hypotheses, the study findings revealed that abusive supervision is negatively related to moral courage whereas moral efficacy is positively related to courage. Furthermore, moral efficacy moderates the abusive supervision-moral courage relationship in such a way that the negative association between abusive

supervision and moral courage is reduced when moral efficacy is high.

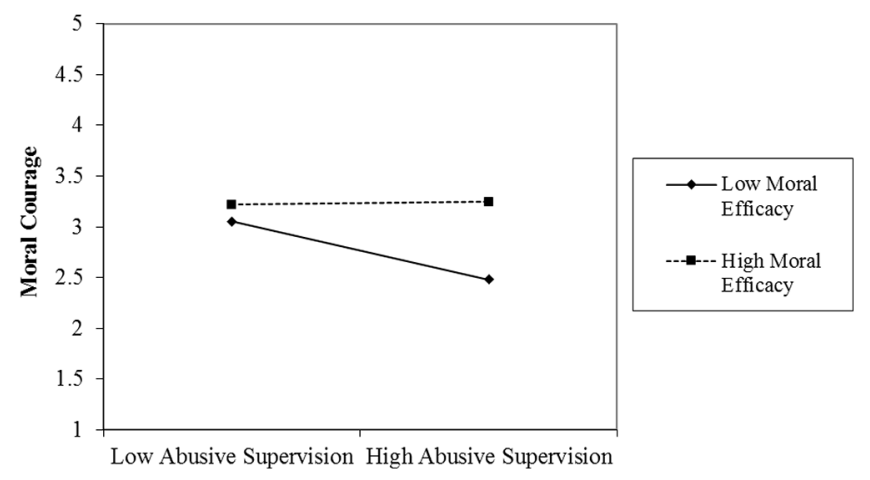

Abusive
supervision
and moral
courage

151 


\section{PRR}

3,2

\section{Theoretical implications}

This study made a number of contributions to the literature. First, the study responded to calls for more research on the relationship between undesirable leadership behaviours, such as supervisory abuse, and ethical outcomes, such as moral courage (Hannah et al., 2011a, 2011b, 2013). Consistent with both power-dependence (Emerson, 1972) and social exchange (Cropanzano and Mitchell, 2005) theories, as well as prior research findings on the relationship between supervisory abuse and prosocial behaviours (Rafferty and Restubog, 2011; Hannah et al., 2013; Wang and Jiang, 2015), the study found that abusive supervision is negatively related to moral courage. This confirms that, because of the power difference, subordinates are usually discouraged from challenging abusive supervisors and are more likely to reciprocate their negative treatment by withholding morally courageous acts (Tepper et al., 2007; Tepper et al., 2009; Rafferty and Restubog, 2011; Hannah et al., 2013; Wang and Jiang, 2015). This will help them rebalance the exchange relationship with their supervisors and at the same time avoid relational deterioration with them (Tepper et al., 2007; Tepper et al., 2009; Hannah et al., 2013). The study also addressed calls for more research on the link between moral efficacy and moral courage (Baumert et al., 2013). In line with Lee et al. (2017), who found that moral efficacy is positively related to acting boldly in organizations, the study findings revealed that moral efficacy is positively related to moral courage ( $\beta=0.232$ ). This confirms that moral efficacy is "one likely foundation for moral courage" and that for individuals to act with moral courage, they need to feel competent to act (May et al., 2014, p. 71). It is worth noting that both abusive supervision and moral efficacy explained a small proportion of the variance in moral courage $\left(R^{2}=0.057\right.$ for abusive supervision and $R^{2}=0.061$ for moral efficacy). As mentioned before, very little is known about the antecedents of moral courage (Hannah and Avolio, 2010; Hannah et al., 2011a, 2011b; May et al., 2014). However, researchers argue that other factors such as group norms and moral meaningfulness could affect the decision to act in a morally courageous way (Sekerka and Bagozzi, 2007; May et al., 2014). Therefore, future research may wish to consider the relationship between these factors and moral courage.

Finally, this study addressed calls for research on the personal factors that could mitigate the undesirable effects of abusive supervision (Harvey et al., 2007; Tepper et al., 2017). Specifically, the study contributed to the literature by examining the moderating role of moral efficacy on the relationship between abusive supervision and moral courage. The findings revealed that moral efficacy moderates the relationship between abusive supervision and moral courage in such a way that the negative relationship between both variables is weaker for employees with high rather than low levels of moral efficacy. This suggests that moral efficacy is a resource that helps some employees cope with abusive supervision more effectively than others (Zhang et al., 2014). This is also consistent with behavioural plasticity theory and confirms that when employees are high in moral efficacy, they are less likely to be negatively affected by external forces such as supervisory abuse (Eden and Aviram, 1993).

\section{Practical implications}

The study findings suggest that supervisory abuse may reduce followers' courage to translate ethical intentions into actions. Therefore, organizations should avoid hiring managers or supervisors who are disposed to mistreating others and displaying hostile behaviours. They could use integrity tests when hiring supervisors and could include questions related to ethical dilemmas and the treatment of subordinates in the interview process (Mostafa, 2018). Organizations should also identify abusive supervisors and offer them abuse-prevention training to circumvent their hostile behaviour. This is important, especially that the malicious effects of abusive supervision are very costly to organizations (Zhang et al, 2014). Even though 
abusive supervisors are usually not easy to detect (Tepper et al., 2007), practices such as seeking feedback from subordinates or 360-degree appraisals may help identify such supervisors and offer them developmental or disciplinary attention (Hannah et al., 2013).

The study findings also suggest that moral efficacy is important for stimulating moral courage and that the negative influence of abusive supervision on moral courage is more severe for individuals with low moral efficacy. Therefore, organizations should pay more attention to moral efficacy when recruiting and selecting employees. Specifically, they could recruit and select individuals based on their confidence and ability to deal with ethical dilemmas and apply ethical solutions to problems. Organizations should also consider follower moral efficacy when matching supervisors with followers. They also need to identify employees with low moral efficacy, pay special attention to them and ensure that their supervisors do not treat them with abuse and treat them respectfully and fairly (Zhang et al., 2014). Organizations could also promote employees moral efficacy through practices such as mastery experiences, mentoring and social learning (Hannah et al., 2011a, 2011b; Neumeister, 2017).

\section{Limitations}

The study has a number of limitations. First, because of the cross-sectional design of the study, inferences regarding causality cannot be made. For example, it is possible that employees with low moral courage might actually view their supervisors as abusive. Longitudinal or experimental research would be very useful in this regard. Second, as all the study data were collected from the same respondents at the same point in time, common method bias might have possibly influenced the study findings. However, it should be noted that finding interaction effects helps rule out common method bias because this type of bias severely deflates interaction terms and cannot account for significant interactions (Siemsen et al., 2010; Podsakoff et al., 2012). Nevertheless, future research can minimize common method bias concerns by collecting data from multiple sources and at different points in time. The final limitation relates to the generalizability of the study findings. The study data were obtained from nurses in a single public hospital in Egypt. Therefore, more research is needed to identify whether the results of this study apply in other contexts.

\section{References}

Anderson, J.C. and Gerbing, D.D. (1988), "Structural equation modelling in practice: a review and recommended two-step approach", Psychological Bulletin, Vol. 103 No. 3, pp. 411-423.

Aquino, K., Tripp, T.M. and Bies, R.J. (2006), "Getting even or moving on? Power, procedural justice, and types of offense as predictors of revenge, forgiveness, reconciliation, and avoidance in organizations", Journal of Applied Psychology, Vol. 91 No. 3, pp. 653-668.

Ashforth, B. (1994), "Petty tyranny in organizations", Human Relations, Vol. 47 No. 7, pp. 755-778.

Baumert, A., Halmburger, A. and Schmitt, M. (2013), "Interventions against norm violations: Dispositional determinants of self-reported and real moral courage", Personality and Social Psychology Bulletin, Vol. 39 No. 8, pp. 1053-1068.

Bottomley, P., Mostafa, A.M.S., Gould-Williams, J.S. and Leon-Cazares, F. (2016), "The impact of transformational leadership on organizational citizenship behaviours: the contingent role of public service motivation", British Journal of Management, Vol. 27 No. 2, pp. 390-405.

Brislin, R.W. (1970), "Back-translation for cross-cultural research”, Journal of Cross-Cultural Psychology, Vol. 1 No. 3, pp. 185-216.

Chang, S.J., Van Witteloostuijn, A. and Eden, L. (2010), "From the editors: common method variance in international business research", Journal of International Business Studies, Vol. 41 No. 2, pp. 178-184. 
PRR

3,2

Cropanzano, R. and Mitchell, M.S. (2005), "Social exchange theory: an interdisciplinary review”, Journal of Management, Vol. 31 No. 6, pp. 874-900.

Eden, D. and Aviram, A. (1993), "Self-efficacy training to speed reemployment: helping people to help themselves", Journal of Applied Psychology, Vol. 78 No. 3, pp. 352-360.

Emerson, R.M. (1972), "Exchange theory. Part I: a psychological basis for social exchange”, in Berger, J., Zelditch, M. and Anderson, B. (Eds). Sociological Theories in Progress, Vol. 2, Houghton-Mifflin, Boston, MA, pp. 38-57.

Fornell, C. and Larcker, D.F. (1981), "Structural equation models with unobserved variables and measurement error: Algebra and statistics", Journal of Marketing Research, Vol. 18 No. 3, pp. 382-388.

Greitemeyer, T., Fischer, P., Kastenmueller, A. and Frey, D. (2006), "Civil courage and helping behaviour: differences and similarities", European Psychologist, Vol. 11 No. 2, pp. 90-98.

Hannah, S.T. and Avolio, B.J. (2010), "Moral potency: building the capacity for character-based leadership”, Consulting Psychology Journal: Practice and Research, Vol. 62 No. 4, pp. 291-310.

Hannah, S.T., Avolio, B.J. and May, D.R. (2011a), "Moral maturation and moral conation: a capacity approach to explaining moral thought and action", Academy of Management Review, Vol. 36 No. 4, pp. 663-685.

Hannah, S.T., Avolio, B.J. and Walumbwa, F.O. (2011b), "Relationships between authentic leadership, moral courage, ethical and pro-social behaviors", Business Ethics Quarterly, Vol. 21 No. 4, pp. 555-578.

Hannah, S.T., Schaubroeck, J.M., Peng, A.C., Lord, R.G., Trevino, L.K., Kozlowski, S.W.J., Avolio, B.J., Dimotakis, N. and Doty, J. (2013), "Joint influences of individual and work unit abusive supervision on ethical intentions and behaviors: a moderated mediation model", Journal of Applied Psychology, Vol. 98 No. 4, pp. 579-592.

Harvey, P., Stoner, J., Hochwarter, W. and Kacmar, C. (2007), "Coping with abusive bosses: the neutralizing effects of ingratiation and positive affect on negative employee outcomes", The Leadership Quarterly, Vol. 18 No. 3, pp. 264-280.

Lee, D., Choi, Y., Youn, S. and Chun, J. (2017), "Ethical leadership and employee moral voice: the mediating role of moral efficacy and the moderating role of leader-follower value congruence", Journal of Business Ethics, Vol. 141 No. 1, pp. 47-57.

Little, T.D., Bovaird, J.A. and Widaman, K.F. (2006), "On the merits of orthogonalizing powered and product terms: implications for modeling interactions among latent variables", Structural Equation Modeling: A Multidisciplinary Journal, Vol. 13 No. 4, pp. 497-519.

May, D.R., Chan, A.Y.L., Hodges, T.D. and Avolio, B.J. (2003), "Developing the moral component of authentic leadership", Organizational Dynamics, Vol. 32 No. 3, pp. 247-260.

May, D.R., Luth, M.T. and Schwoerer, C.E. (2014), "The influence of business ethics education on moral efficacy, moral meaningfulness, and moral courage: a quasi-experimental study", Journal of Business Ethics, Vol. 124 No. 1, pp. 67-80.

Mostafa, A.M.S. (2018), "Ethical leadership and organizational citizenship behaviours: the moderating role of organizational identification", European Journal of Work and Organizational Psychology, Vol. 27 No. 4, pp. 441-449.

Neumeister, J.R. (2017), "The model of transformational change for moral action: a conceptual framework to elevate student conduct practice in higher education", Journal of College and Character, Vol. 18 No. 2, pp. 97-111.

Olsthoorn, P. (2013), "Virtue ethics in the military", in van Hooft, S. and Saunders, N. (Eds), The Handbook of Virtue Ethics, Acumen Publishing, Cape Town, pp. 365-374.

Osswald, S., Greitemeyer, T., Fischer, P. and Frey, D. (2009), "What is moral courage? Definition, explication and classification of a complex construct", in Pury, C. and Lopez, S. (Eds), The Psychology of Courage: Modern Research on an Ancient Virtue, American Psychological Association, Washington, DC, pp. 94-120.

Podsakoff, P.M., MacKenzie, S.B. and Podsakoff, N.P. (2012), "Sources of method bias in social science research and recommendations on how to control it", Annual Review of Psychology, Vol. 65, pp. 539-569. 
Priesemuth, M. (2013), "Stand up and speak up: employees' prosocial reactions to observed abusive supervision", Business and Society, Vol. 52 No. 4, pp. 649-665.

Rafferty, A.E. and Restubog, S.L.D. (2011), "The influence of abusive supervisors on followers' organizational citizenship behaviours: the hidden costs of abusive supervision", British Journal of Management, Vol. 22 No. 2, pp. 270-285.

Saks, A.M. and Ashforth, B.E. (2000), "The role of dispositions, entry stressors, and behavioural plasticity theory in predicting newcomers' adjustment to work", Journal of Organizational Behavior, Vol. 21 No. 1, pp. 43-62.

Abusive
supervision
and moral
courage

155

Schaubroeck, J.M., Hannah, S.T., Avolio, B.J., Kozlowski, S.W.J., Lord, R.G., Treviño, L.K., Dimotakis, N. and Peng, A.C. (2012), "Embedding ethical leadership within and across organization levels", Academy of Management Journal, Vol. 55 No. 5, pp. 1053-1078.

Sekerka, L.E. and Bagozzi, R.P. (2007), "Moral courage in the workplace: moving to and from the desire and decision to act", Business Ethics: A European Review, Vol. 16 No. 2, pp. 132-149.

Siemsen, E., Roth, A. and Oliveira, P. (2010), "Common method bias in regression models with linear, quadratic, and interaction effects”, Organizational Research Methods, Vol. 13 No. 3, pp. 456-476.

Sulea, C., Fine, S., Fischmann, G., Sava, F.A. and Dumitru, C. (2013), "Abusive supervision and counterproductive work behaviours: the moderating effects of personality", Journal of Personnel Psychology, Vol. 12 No. 4, pp. 196-200.

Tepper, B.J. (2000), “Consequences of abusive supervision”, Academy of Management Journal, Vol. 43, pp. $178-190$.

Tepper, B.J. (2007), “Abusive supervision in work organizations: review, synthesis, and research agenda", Journal of Management, Vol. 33 No. 3, pp. 261-289.

Tepper, B.J., Moss, S., Lockhart, D. and Carr, J. (2007), “Abusive supervision, upward maintenance communication, and subordinates' psychological distress", Academy of Management Journal, Vol. 50, pp. 1169-1180.

Tepper, B.J., Carr, J.C., Breaux, D.M., Geider, S., Hu, C. and Hua, W. (2009), “Abusive supervision, intentions to quit, and employees' workplace deviance: a power/dependence analysis", Organizational Behavior and Human Decision Processes, Vol. 109 No. 2, pp. 156-167.

Tepper, B.J., Simon, L. and Park, H.M. (2017), “Abusive supervision”, Annual Review of Organizational Psychology and Organizational Behavior, Vol. 4 No. 1, pp. 123-152.

Wang, R. and Jiang, J. (2015), "How abusive supervisors influence employees' voice and silence: the effects of interactional justice and organizational attribution", The Journal of Social Psychology, Vol. 155 No. 3, pp. 204-220.

Zhang, H., Kwan, H.K., Zhang, X. and Wu, L.-Z. (2014), "High core self-evaluators maintain creativity: a motivational model of abusive supervision", Journal of Management, Vol. 40 No. 4, pp. 1151-1174.

Zhu, W., Riggio, R.E., Avolio, B.J. and Sosik, J.J. (2011), "The effect of leadership on follower moral identity: does transformational/transactional style make a difference?", Journal of Leadership and Organizational Studies, Vol. 18 No. 2, pp. 150-163.

\section{Corresponding author}

Ahmed Mohammed Sayed Mostafa can be contacted at: ahmedmsmostafa@gmail.com

For instructions on how to order reprints of this article, please visit our website:

www.emeraldgrouppublishing.com/licensing/reprints.htm

Or contact us for further details: permissions@emeraldinsight.com 